\title{
Pandemia y huida de las aglomeraciones. La nueva demanda de alojamientos en entornos menos densos y en contacto con la vegetación y la fauna
}

\author{
Joan Amenós Álamo \\ Profesor titular de Derecho Administrativo \\ Universidad Autónoma de Barcelona \\ ORCID: 0000-0002-5957-4338
}

Cita recomendada. AMENÓS ÁLAMO, J., Pandemia y huida de las aglomeraciones. La nueva demanda de alojamientos en entornos menos densos y en contacto con la vegetación y la fauna, dA. Derecho Animal (Forum of Animal Law Studies) 11/4 (2020). - DOI https://doi.org/10.5565/rev/da.533

\section{Resumen}

En este trabajo se examina el encaje jurídico de la demanda de aumento de zonas verdes y de contacto con la naturaleza tras la pandemia de COVID-19. En concreto, se examina esta cuestión tanto en las zonas urbanas ya consolidadas como en las de nuevo crecimiento y en las zonas rurales o bajo protección especial. Estamos ante un evidente rechazo de la idea de aglomeración y ante un incremento de la presión favorable a la construcción de viviendas en zonas rurales y boscosas. Por otra parte, la legislación deberá favorecer el aumento de los espacios verdes en los ámbitos urbanos. Esto podría implicar un reajuste en las relaciones del ser humano con otras especies vegetales y animales adaptadas a un entorno antrópico.

Palabras clave: urbanización dispersa; suelo urbano; suelo rural; parques naturales; vegetación urbana; fauna urbana.

Abstract - Pandemic and the flight from the masses. The new demand for accommodation in less dense
environments in contact with vegetation and fauna

This paper examines the legal fit of the demand for increased green areas and contact with nature following the COVID-19 pandemic. In particular, this issue is examined both in established urban areas and new growth areas and in rural zones or those under special protection. We are facing an evident rejection of the idea of build-ups and an increase in pressure to build in rural and wooded areas. Furthermore, legislation should favour an increase in green spaces in urban areas. This could imply a readjustment of human relationships with other plant and animal species adapted to an anthropic environment.

Keywords: sprawl; urban land; rural land; natural parks; urban vegetation; urban fauna. 


\section{Sumario}

1. Introducción. Límites del trabajo

2. Zonas verdes y grandes epidemias

2.1. Previsibilidad científica e imprevisión relativa de la pandemia desde el punto de vista de la salud pública

2.2. La renovación de la conciencia ecológica o, más bien, una nueva demanda de verdor. ¿Reedición del debate entre la ciudad compacta y densa y el poblamiento disperso?

2.3. Los grados jurídicos del verdor

3. Creación y multiplicación de espacios verdes en el ámbito urbano

3.1. Diseño urbano y protección del "microverdor"

3.2. Los estándares de zonas verdes

4. La salvaguardia de los suelos rurales, no urbanizables o bajo especial protección

4.1. El concepto. Las diferentes tipologías y finalidades

4.2. Estatuto del suelo rural o no urbanizable

4.3. Los parques y espacios naturales

Conclusiones

Bibliografía

\section{Introducción. Límites del trabajo}

En el presente artículo se examina el renovado interés de la sociedad por los espacios libres y las zonas verdes, que se ha incrementado a causa de la pandemia de covid-19 y de las medidas aplicadas para contenerlo (especialmente, el confinamiento de poblaciones). A partir de ello, describiré sucintamente el cuadro legal sobre el que va a operar esa renovada demanda. En primer lugar, el suelo urbano (y su ampliación de terrenos libres o cubiertos de un tapiz vegetal) y, posteriormente, los terrenos agrarios o no urbanizables, que han aumentado su atractivo. Aunque es pronto para cualquier previsión, el rechazo social de las aglomeraciones podría favorecer la suavización de la densidad urbana y edificatoria. Nuestro campo de trabajo es el ordenamiento jurídico español, detectando los puntos comunes que comparten tanto la legislación estatal como la de las Comunidades Autónomas.

\section{Zonas verdes y grandes epidemias}

\subsection{Previsibilidad científica e imprevisión relativa de la pandemia desde el punto de vista de la salud pública}

Los expertos ya habían acumulado considerable información sobre el virus denominado covid-19, si bien se abrigaban muchas dudas sobre su forma concreta de actuar. Los historiadores analizarán los hipotéticos retardos de las autoridades chinas en la adecuada comunicación de la situación epidemiológica y la incertidumbre que rondaba ya desde finales del 2019. Ahora bien, es posible distinguir -al menos, a nivel conceptual- entre la evaluación científica y la subsiguiente respuesta por parte de los sistemas de salud pública. En este sentido, puede afirmase que, en gran parte, ha ocurrido como en el famoso cuento de Pedro el pastor, que anunciaba la llegada del lobo en una situación de generalizada incredulidad ${ }^{1}$. En muy pocas semanas, los aparatos sanitarios nacionales organizaron la respuesta, con un esquema más o menos común de confinamiento (con diferentes grados de severidad y duración), vigilancia (dentro de las posibilidades

\footnotetext{
${ }^{1}$ Como botón de muestra, baste decir que la famosa reunión anual de Davos del Foro Económico Mundial, celebrada los días 21 al 24 de enero del 2020, no incluía ninguna ponencia sobre el coronavirus y se limitaba principalmente al estudio de las previsiones económicas, las perspectivas del cambio climático, las cuestiones raciales y el fomento de la ideología de género. Sólo se da cuenta para el 22 de enero de una "Alianza Mundial en materia de vacunación", que analizaba los resultados obtenidos desde el año 2000 en enfermedades ya tradicionales y conocidas. Menos de dos meses después de Davos, sus premisas saltaban por los aires. Puede consultarse el programa de conferencias en https://es.weforum.org/events/world-economic-forum-annual-meeting-2020 [Última consulta: 22 de septiembre 2020].

34 Derecho Animal. Forum of Animal Law Studies, vol. 11/4
} 
limitadas que en un primer momento ofrecían los análisis) y tratamiento farmacológico y hospitalario (con abundantes dudas en la comunidad médica y bajo un riesgo evidente y cercano de colapso asistencial).

Independientemente de la evolución futura de la pandemia, lo cierto es que la humanidad se halla ante un banco de pruebas de un virus con una mortalidad mayor que la gripe común -pero no exagerada- y con una relativa capacidad de contagio (a diferencia de otros virus más contagiosos y más letales). Los ciudadanos, las Administraciones Públicas y los dispositivos sanitarios deberán extraer enseñanzas de cara al futuro, ya que la alta concentración de fauna estabulada y la sociedad de grandes congregaciones urbanas y transporte masivo de personas y bienes son un campo abonado para nuevas epidemias ${ }^{2}$.

También se han vivido tiempos convulsos desde el punto de vista jurídico, con muchísimas dificultades para encajar el Derecho de la emergencia en los diversos marcos constitucionales y con el riesgo evidente de que lo excepcional se vaya convirtiendo en lo normal ${ }^{3}$. Entre los muchos campos afectados destaca, por ejemplo, la cuestión de la vivienda. Los múltiples efectos pueden leerse en el informe de la OECD "Housing amid Covid-19: policy responses and challenges"4 y abarcan desde el impacto económico en el sector hasta las relaciones jurídicas entre propietarios, inquilinos y prestamistas hipotecarios. Ello incluye, por supuesto, la irrupción del teletrabajo y, como horizonte inmediato, la demanda de una mayor flexibilidad que posibilite los cambios de residencia de acuerdo con las nuevas inquietudes. Vemos esto con más calma.

\subsection{La renovación de la conciencia ecológica o, más bien, una nueva demanda de verdor. ¿Reedición del debate entre la ciudad compacta y densa y el poblamiento disperso?}

Como hemos dicho anteriormente, una de las características de la pandemia ha sido, sobre todo en las primeras semanas, una evidente preeminencia de las respuestas nacionales, diferenciadas y adaptadas a los medios y a los daños detectados en cada país. Ello no excluye, por supuesto, que hayan operado organismos supranacionales (por ejemplo, la discutida Organización Mundial de la Salud o los apoyos financieros del Fondo Monetario Internacional y de la Unión Europea).

En este contexto, dos medidas adoptadas ampliamente han golpeado la vida cotidiana. Me refiero al confinamiento (con esas impresionantes fotografías de las grandes ciudades occidentales totalmente desiertas) $\mathrm{y}$, en segundo lugar, las diversas instrucciones, de distancia social y limitación del número de relaciones (restricciones en el aforo de establecimientos, en los viajes, etc.). Estos mandatos han afectado a todas las agrupaciones humanas -aldeas, pequeños o grandes municipios, conurbaciones...-, pero es evidente que han sido mucho más disruptivas en las urbes y áreas metropolitanas de mayor densidad.

Ha rejuvenecido así el viejo debate entre la urbanización dispersa y las ciudades compactas ${ }^{5}$. Se decía que estas últimas exhibían un balance ecológico favorable, ya que utilizaban -en principio- menos espacio para habitar y producir y, por tanto, mantenían la virginidad de los espacios forestales y rurales. Además, la misma concentración permitía un uso eficiente del transporte público y la reducción del empleo del automóvil. Por el contrario, la dispersión de emplazamientos se mostraba -aparentemente- demasiado voraz en la utilización del suelo. A ello se añadía la difícil implantación del transporte colectivo -sobre todo, del ferrocarril- en una red capilar de poblamiento. El coche, no obstante, sí puede adaptarse a estas estructuras dendríticas (y las sostiene, porque es imprescindible en ellas).

En el contexto de la pandemia, el enemigo a batir es la aglomeración de personas. Partiendo de este dato, ha habido un intento de resucitar la discusión sobre los dos modelos arriba expuestos. Así, se ha dicho que las urbanizaciones de baja densidad constituían una respuesta espacial adecuada contra la infección. Esto sólo es parcialmente cierto, teniendo en cuenta las formas de transmisión que emplea este coronavirus (por ejemplo, con el simple desplazamiento de individuos contagiados pero asintomáticos). Por otro lado, sería extraño que las decisiones futuras sobre la articulación urbana se guiaran principalmente por el criterio epidemiológico, ya que -a lo largo de la historia- las ciudades han nacido siempre en base a múltiples razones (la economía, las políticas públicas en juego, las necesidades defensivas, etc.). De todos modos, se advierten en el siglo XIX en Occidente algunas manifestaciones de poblamiento disperso estimuladas por la huida de

\footnotetext{
${ }^{2}$ Las enseñanzas no sólo se hallan en las ciencias prospectivas, sino también en la historia, como ha demostrado Kyle Harper con su análisis de la influencia de ciertas epidemias en la decadencia del Imperio Romano, v. HARPER, K., Fate of Rome: Climate, Disease, and the End of an Empire (Princeton 2017).

${ }^{3}$ Es inabarcable el conjunto de artículos y libros que ya han comentado la pandemia desde el punto de vista jurídico. Baste citar aquí, por su relevancia y por su anticipación en las primeras semanas, el número especial núm. 86-87 (marzo-abril 2020) de la revista $E l$ Cronista del Estado Social y de Derecho, que integra diversos artículos y que lleva por título "Coronavirus...y otros problemas".

4 OECD, "Housing amid Covid-19: policy responses and challenges", 2020 (22 de Julio), disponible en https://read.oecdilibrary.org/view/?ref=135 135322-lju8yj5sib\&title=Housing-Amid-Covid-19-Policy-Responses-and-Challenges.

${ }^{5}$ Sobre esto, v. AMENÓS ÁLAMO, J., El mito legal de la ciudad compacta (Barcelona 2015). A nivel global, sigue siendo insustituible la obra de BRUEGMANN, R., Sprawl. A compact history (The University of Chicago 2005).
} 
las infecciones u otros motivos sanitarios ${ }^{6}$.

En realidad, sólo una visión miope centrada en el presente nos haría olvidar que, a lo largo de la historia, las epidemias y las plagas ya han condicionado intensamente tanto la forma de las ciudades como la vivienda. En este sentido, MEGAHED y GHONEIM $^{7}$ señalan tres aspectos que, en los dos últimos siglos, han sido afectados por tales situaciones problemáticas:

- La renovación urbana y su lucha contra la acumulación y en favor de la idea de aclarar y expandir los cascos urbanos.

- Las reformas del sistema de suministro de agua y alcantarillado.

- Ciertos cambios en la vivienda que tienden a reforzar la idea de limpiez y simplicidad, contra la suciedad y la sobrecarga.

Dicho lo anterior, debe reconocerse que la pandemia es un golpe a la imagen ecológicamente ideal de la ciudad compacta. No sólo eso. Se observa, además, una incipiente querencia de los ciudadanos de residir o simplemente viajar- por ámbitos de reducida concentración, por espacios más abiertos. El avance del teletrabajo también puede favorecer esta dirección. De todos modos, la observación de estas tendencias tiene aún un carácter prematuro y el tiempo confirmará o no el crecimiento de estas semillas. De todos modos, para algunos autores, las cartas ya están echadas y la pandemia ha supuesto un zarpazo ya permanente contra la demanda de densidad ${ }^{8}$.

\subsection{Los grados jurídicos del verdor}

Como ya hemos dicho, se observa un mayor interés por los lugares poco concurridos y con una presencia abundante de vegetación. Disponemos de un ejemplo que no es cuantificable, pero que fue visible al suavizarse el confinamiento: el disfrute alegre e inmediato de los espacios verdes por parte de hombres, mujeres y niños. Bastaba un parque para calmar ese anhelo de "naturaleza", que algunos llegaron a satisfacer perdiéndose por bosques frondosos y andurriales solitarios. El éxito del turismo rural este último verano ha ido en la misma dirección.

Por tanto, podemos anotar un aumento en la demanda de espacios libres y con una presencia más o menos amplia de terrenos con tapiz vegetal o carentes de edificaciones. Son territorios que cubren funciones de protección ambiental y que, además, contribuyen al bienestar psicológico de la población. El ordenamiento jurídico se ha preocupado tradicionalmente de su tutela, mantenimiento y ampliación.

Ahora bien, el gran salto en su salvaguardia se produce en la segunda mitad del siglo XX. Dejando ahora de lado la preocupación ambientalista, hemos de citar aquí los Principios de Urbanismo, más conocidos como La Carta de Atenas, debidos a la pluma de Le Corbusier. Con ellos, se interpreta que la protección y el aumento de la vegetación deben ser una auténtica política pública y que la aparición de árboles y otras plantas en la ciudad no puede dejarse en manos de jardines particulares ${ }^{9}$.

Desde el punto de vista legal y urbanístico (e incluso sociológico), cabe distinguir dos grandes ámbitos en nuestro análisis. Por un lado, los terrenos vegetales que radican en suelos jurídicamente clasificados como urbanos. Es el verde urbano que, como hemos visto, reclamaba Le Corbusier. En segundo lugar, las masas silvícolas y/o agrarias que se sitúan en suelos que el ordenamiento califica como rurales o no urbanizables. Se trata, en este segundo caso, de la inmensa tarea de protección de la biodiversidad. Lo veremos después con mayor detenimiento. Sin embargo, conviene hacer una aclaración. Este trabajo no pretende reflexionar, aunque los tiene en cuenta, sobre los motivos ecológicos, culturales, estéticos o éticos que legitiman su salvaguarda. Más bien, me interesa indicar dónde va a encajarse esa demanda un tanto difusa de menor

\footnotetext{
${ }^{6}$ Así ocurrió a lo largo de todo el siglo XIX y principios del XX en Barcelona y en diversas poblaciones que estaban a una distancia que permitía la huida de las diversas epidemias que asolaron la ciudad en esa época. Sobre ello, es interesante el testimonio recogido por Juan Ramón MASOLIVER en su artículo "De quan Montcada fou peonera", cuya versión en castellano se recogió en su libro "Perfil de sombras" (Barcelona 1994) 47-51.

${ }^{7}$ MEGAHED, N.A. y GHONEIM, E.M., Antivirus-built environment: lessons learned from Covid-19 pandemic (2020) 1-2, disponible en https://www.ncbi.nlm.nih.gov/pmc/articles/PMC7313520/.

${ }^{8}$ Así lo indican, para el mercado norteamericano de vivienda, SITIAN LY y YITCHEN SU, The impact of the Covid-19 pandemic on the demand for density: evidence from the U.S. housing market, Federal Reserv. Bank of Dallas (July 27, 2020). Disponible en internet: https://www.dallasfed.org/-/media/documents/research/papers/2020/wp2024.pdf

${ }^{9}$ Así, en el Principio número 11, se afirmaba lo siguiente: "El crecimiento de la ciudad devora progresivamente las superficies verdes, limítrofes de sus sucesivas periferias. Este alejamiento cada vez mayor de los elementos naturales aumenta en igual medida el desorden de la higiene". Véase este principio y su comentario en LE CORBUSIER, Principios de urbanismo (La Carta de Atenas), trad. castellana de Juan-Ramón CAPELLA (Barcelona 1981) 40-41.
} 
densidad y mayor contacto con elementos vegetales y animales. No es propiamente un deseo de sostener la biodiversidad -aunque también lo es-, ni tampoco un prurito estético -aunque lo bello es esencial para el ser humano-, ni una expresión de misericordia ante la vida animal -aunque esto va de soi-. Es una razonable tendencia en favor de un entorno menos macizo, donde se huela y se contemple la hierba y el árbol, sin necesidad de apilarse en apretujadas concentraciones metropolitanas que, en este momento histórico, han mostrado algunas desventajas graves.

Antes de continuar, conviene hacer una aclaración sobre la vida de los animales en estos parajes. Tanto en espacios dominados por las construcciones erigidas por el hombre como en los ámbitos menos antrópicos, la fauna está siempre presente. Lo único que ocurre es que las especies son diferentes y siguen diversas pautas adaptativas (o desaparecen o huyen, ciertamente). Todo ello se plasma en la división convencional entre fauna urbana y fauna silvestre ${ }^{10}$.

Así, en las áreas urbanas observamos dos grandes conjuntos: por un lado, la más o menos numerosa presencia de mascotas y, por otra parte, los animales perfectamente adaptados a las ciudades -desde las prolíficas ratas hasta multitud de pájaros que conviven habitualmente con nosotros y que constituirían una especie de fauna asilvestrada pero integrada en la urbe ${ }^{11}$. En cambio, las zonas rurales y forestales facilitan la subsistencia de especies salvajes, aunque en muchas ocasiones dependientes de la actividad humana (por ejemplo, las aves que precisan de un entorno agrícola).

En cada caso, las relaciones del ser humano con estos animales son diferentes y cubren diversas funciones. Por ejemplo, el equilibrio ecológico y la biodiversidad en los espacios naturales, el soporte psicológico en el caso de la fauna de compañía o la simple contemplación de la belleza (como ocurre con ciertas aves). Esta pluralidad de justificaciones ya nos ha aparecido anteriormente en relación a los terrenos. Pues bien, nuestra perspectiva es el estudio de una demanda que engloba todas esas legitimaciones.

Evidentemente, he formulado un bosquejo que ni siquiera incluye a la ganadería (intensiva o extensiva) o a los invertebrados. Obsérvese, no obstante, que nuestra percepción de cada una de las bestias parte de la función que cubren con respecto al ser humano ${ }^{12}$. Así, se fomenta la tarea benefactora en el caso de la mascota, represiva si la especie implica un peligro (piénsese en los roedores urbanos -la rata parda- o en la otrora frecuente desecación de marismas) o relativamente protectora si la especie favorece la estabilidad ecológica general (como ocurre con las poblaciones más agrestes). En el caso de la ganadería, simplemente estamos ante el fomento de la producción por motivos alimenticios.

\section{Creación y multiplicación de espacios verdes en el ámbito urbano}

\subsection{Diseño urbano y protección del "microverdor"}

El suelo urbano dispone de los servicios esenciales (y habituales en los núcleos de población) de asfaltado, encintado de aceras, iluminación y suministro de agua, gas y electricidad, quedando normalmente situado en un ámbito de edificación ya predominante y consolidada ${ }^{13}$. De cara a la elaboración de los planes urbanísticos (que son normas de rango reglamentario), se trata de un concepto reglado. Es decir, el planificador -la Administración Pública- clasificará como urbanos los terrenos que ya cumplen tales condiciones. En las ciudades ya construidas, el verdor aparece normalmente bajo la forma de elementos vegetales en terrenos privados o de parque urbano de titularidad y acceso público (que forma parte, junto a equipamientos e infraestructuras, de los legalmente denominados "sistemas generales" o soporte fundamental de la urbe). Además, suele ser relevante la presencia de elementos vegetales aislados (arbolado en calles y avenidas, jardines, etc.).

Los terrenos para el incremento de la superficie de los parques públicos se obtienen normalmente

\footnotetext{
${ }^{10}$ Pueden consultarse estos conceptos en ZOIDO, F., DE LA VEGA, S., PIÑEIRO, A. MORALES, G., MAS, R., LOIS, R.C., y GONZÁLEZ, J.M., Diccionario de urbanismo. Geografía urbana y ordenación del territorio (Madrid 2013). Véanse especialmente las entradas "Fauna urbana" (p.174) y "Calidad ambiental urbana" (p.56).

${ }^{11}$ En la fauna urbana española, se han destacado como aves habituales la paloma, el vencejo, la grajilla, el gorrión y el cernícalo común (V. ZOIDO et alii, op.cit., p.174).

${ }^{12}$ Hace furor el debate sobre los derechos de los animales. Nuestra postura es que no hay manera de atribuir derechos a unos seres que carecen de conciencia y voluntad para ejercerlos. Sobre esto, me remito a ALLÍ-TURRILLAS, J.C., La protección de la biodiversidad. Estudio jurídico de los sistemas para la salvaguarda de las especies naturales y sus ecosistemas (Madrid 2016) 52 y ss. y la bibliografía allí citada). Ello no impide su protección, ya sea por sus valores propios (posición que suele denominarse "trascendentalista" o ética) o por su función en el ecosistema. Por nuestra parte, nos sentimos cómodos en la corriente del antropocentrismo utilitarista: los protegemos porque nos son útiles, porque sirven a la única especie que ha tomado conciencia de su soledad y finitud en el universo y que está dispuesta a ejercer voluntariamente su capacidad de compasión, misericordia y acogida.

${ }^{13}$ Para la precisión y matices sobre el concepto de suelo urbano (ahora también denominado "suelo urbanizado", me remito a BAÑO LEÓN, J.M, Derecho urbanístico común (Madrid 2009) 110 y ss.
} 
mediante expropiación forzosa o por imperativo de las cesiones urbanísticas exigidas por la ley (es decir, como contrapartida de la atribución de un aprovechamiento urbanístico al titular de un terreno). Ahora bien, la tarea habitual es aquí la mejora cualitativa del verde urbano, hermoseando lo existente y dedicándole las pertinentes partidas presupuestarias ${ }^{14}$.

Las actuales tendencias de rehabilitación, regeneración y renovación urbanas -expresadas, por ejemplo, en la Ley española 8/2013 de 26 de junio- pueden favorecer el aumento de la calidad ambiental y la presencia de vegetación en la ciudad. El legislador español ha construido un delicado mecanismo para la reforma de los suelos urbanos, intentando que los propietarios contribuyan a la ejecución de actuaciones de reforma o renovación en un marco de justa distribución de beneficios y cargas ${ }^{15}$. Ahora bien, es probable que ese esfuerzo deba convivir con una huída -aún minoritaria, pero persistente- de los ciudadanos hacia poblaciones más pequeñas o hacia territorios menos densos. De hecho, un exhausto erario público deberá elegir: o subvenir a la inmensa tarea de la recuperación y mejoramiento urbanos o reactivar las tierras que, bajo un nombre equívoco y oscuro, se incluyen a veces en la "España vacía"16.

\subsection{Los estándares de zonas verdes}

Ahora bien, cuando la ciudad ha de crecer a lo largo de lo que se denomina suelo de reserva urbana o suelo urbanizable, el legislador ha impuesto la presencia de un determinado porcentaje de espacios verdes, que se califica en Derecho urbanístico como estándar legal. En los últimos decenios, ha logrado un gran predicamento (y respaldo legislativo) la fórmula de la arquitectura funcionalista que combina zonas verdes de grandes dimensiones (que alcanzan, pues, altos estándares) y población concentrada en edificios de gran densidad y altura considerable. Esta receta permite una adecuada conexión con la red de transporte público y suele abaratar el precio de las viviendas.

Ahora bien, en los últimos treinta años el dibujo descrito se ha visto en muchas ocasiones rebasado por una pauta que ha encontrado un enorme grado de aceptación (de hecho, ya tenía su propio y amplio público si miramos a la experiencia de otros países occidentales o si reflexionamos simplemente sobre nuestro pasado). Se trata de las zonas calificadas por el planificador como de vivienda unifamiliar, ya sea aislada o adosada. En este caso, dejando ahora de lado la aplicación también en estas áreas de los estándares legales de zonas verdes, es habitual -y muy valorada por sus poseedores- la presencia de elementos vegetales en el espacio circundante a la vivienda (patio, vestíbulos exteriores, etc.). En los últimos años, diversas medidas legislativas han introducido restricciones en contra de esta fórmula de ocupación del territorio de baja densidad.

Sin embargo, es evidente que la pandemia parece haber acentuado la preferencia de los consumidores por la vivienda unifamiliar. De momento, así lo indican algunos titulares periodísticos y la opinión de algunos profesionales implicados en la compraventa inmobiliaria. De todos modos, pronto se podrán elaborar algunas cifras indicativas. Establecer ahora conclusiones sería prematuro y, además, el acordeón urbano de la concentración y la dispersión de la población tiene sus propios ritmos y reglas.

\section{La salvaguardia de los suelos rurales, no urbanizables o bajo especial protección}

\subsection{El concepto. Las diferentes tipologías y finalidades}

Hasta ahora, nos hemos referido al suelo urbano, donde la alfombra verde se inserta en un terreno

\footnotetext{
${ }^{14}$ La creación, el mantenimiento y el perfeccionamiento de los parques y jardines urbanos se considera ordinariamente una mejora de carácter general, que se cubre con el presupuesto de la Administración Pública competente y que no es asumido por las contribuciones especiales de los vecinos colindantes.

${ }^{15}$ No obstante, PARADA y LORA-TAMAYO apuntan gráficamente que "la introducción de estos mecanismos, previstos para el ensanche, para terrenos no ocupados, es la consumación de una lógica que a nuestro juicio tendrá poco éxito puesto que, si ya es difícil poner de acuerdo a una Comunidad de vecinos para hacer las obras de una garaje y establecer una derrama, cuánto más lo será si se pretende que estos se erijan en los nuevos agentes rehabilitadores de la ciudad" [PARADA, R. y LORA-TAMAYO, M., Derecho Administrativo III. Bienes públicos. Derecho urbanístico (Madrid 2019) 397].

${ }^{16}$ En efecto, se trata de una noción que sirve fundamentalmente a la agitación política, pero que es científicamente poco operativa. En primer lugar, es demasiado vago, ya que incluye desde auténticos desiertos hasta urbanizaciones elitistas, pasando por un amplio catálogo de municipios escasamente poblados pero con evidentes diferencias de renta. En segundo lugar, el discurso de la "España vacía" ha de detenerse ante el derecho fundamental del libre desplazamiento. En tercer lugar, en fin, desde el punto de vista ambiental se observan muchas ventajas en la presencia viva de esa masa inmensa de terrenos despoblados y crecientes. En efecto, la FAO y muchos otros organismos nos avisan de que el suelo boscoso ha crecido espectacularmente en los últimos años en los países occidentales (y también en otras regiones). El abandono de la agricultura y su mayor productividad por hectárea de terreno serían la causa principal, pero habría que añadir también la política de reforestación (que China practica a lo grande) y la protección legal. El informe anual de la FAO sobre el estado mundial de los bosques puede leerse en http://www.fao.org/3/ca8642es/CA8642ES.pdf [última consulta: 23 de septiembre de 2020].
}

38 Derecho Animal. Forum of Animal Law Studies, vol. 11/4 
edificado y en un entorno articulado por los servicios propios de la ciudad (tradicionalmente, asfalto de calles y encintado de aceras, alcantarillado y suministro de aguas, gas y electricidad). Ahora bien, la planificación urbanística prevé también la existencia de un suelo rural o no urbanizable, donde ya sólo es posible habitar de forma excepcional (lo mismo ocurre con la actividad productiva, que sólo se admite restrictivamente o en situaciones específicas).

La tipología de estos territorios es múltiple. Así, de entrada, hemos de hablar de un suelo no urbanizable que alcanza tal clasificación no porque tenga unos valores "naturales" especiales, sino porque la autoridad planificadora lo considera inadecuado para el desarrollo urbano (por ejemplo, para evitar justamente la dispersión). Pero existe, además, el terreno no urbano que sí merece, per se, la protección, a causa de su esencia rural o su provecho forestal, estético o incluso histórico. Pues bien, dentro de esta última clase de suelo, aún sería posible distinguir territorios de máximo interés y, por tanto, acreedores de una intensa salvaguardia. Estamos hablando de los espacios naturales especialmente protegidos. En ellos se aplica -como indica su mismo nombre- la legislación de espacios naturales, que es lex specialis respecto a las reglas generales propias de las normas urbanísticas.

\subsection{Estatuto del suelo rural o no urbanizable}

En esta clase de suelo se manifiesta el contenido elemental que, con ciertos límites, alcanza la propiedad inmobiliaria: el terreno con un uso natural y agrario y, con ciertos límites, la vivienda agrícola asociada a ese uso ${ }^{17}$. Las facultades edificatorias que amplíen ese punto de partida serán otorgadas por la determinación discrecional de la Administración Pública a través de un plan urbanístico aprobado legalmente. A este esquema sólo escapa el respeto a lo ya construido, aunque podría ser objeto de expropiación.

Ahora bien, ello no quiere decir que no pueda admitirse un uso residencial en el suelo no urbanizable. Lo que ocurre es que ello tiene un carácter excepcional y su autorización administrativa se rodea de considerables cautelas. Por ejemplo, como ya hemos dicho, la vivienda vinculada a una explotación agraria o incluso el alojamiento unifamiliar aislado. Igualmente, y también bajo algunas restricciones, se admite el emplazamiento de ciertas actividades económicas y de servicios públicos. Nos interesan especialmente los usos recreativos en suelo no urbanizable. Por ejemplo, las fincas con finalidad vacacional, los cámpings, etc.

El conjunto de viviendas que nos han aparecido atraerán un renovado interés entre los consumidores, teniendo en cuenta la cercanía del medio natural y la menor presencia de aglomeraciones. Así se observa, por ejemplo, en el incremento espectacular de las cifras de turismo rural en la presente temporada. Estamos, pues, ante un ámbito revalorizado.

\subsection{Los parques y espacios naturales}

Sigamos dentro del suelo rural o no urbanizable, pero pasemos ahora a los territorios de máxima salvaguardia, a los santuarios cuyas edificaciones y usos sufren la contención más exigente, de cara a asegurar la subsistencia de sus especiales valores rústicos, silvícolas, faunísticos, etc. Las escasas construcciones aquí autorizadas con uso de vivienda (ya sea como vivienda rural o como instalación turística) son, lógicamente, objeto de máxima atracción en la época presente.

Son muchos los problemas jurídicos que se derivan de la implantación de un parque natural, que se efectúa a menudo a través de una Ley especial. Entre ellos, destaca la posible compensación a los titulares de los terrenos que sufren una limitación del estatuto ordinario de la propiedad inmobiliaria (por ejemplo, puede llegar a impedirse cualquier explotación agrícola o forestal). Se trata frecuentemente de vinculaciones singulares que imponen a los propietarios un sacrificio individualizado y desproporcionado. Ni la legislación ni la jurisprudencia han resuelto de forma coherente su derecho a indemnización ${ }^{18}$. En muchos casos, ello se resuelve con un sistema de subvenciones públicas más o menos generosas o estructuradas ${ }^{19}$.

\section{Conclusiones}

\footnotetext{
${ }^{17}$ Para la comprensión de este concepto, sigue siendo fundamental el libro de PAREJA I LOZANO, C., Régimen del suelo no urbanizable (Madrid 1990) 253 y ss.

${ }^{18}$ Sobre ello, v. ALLÍ TURRILLAS, J.C., La protección de la biodiversidad. Estudio jurídico de los sistemas para la salvaguarda de las especies naturales y sus ecosistemas (Madrid 2016) 186-191 y LÓPEZ-RAMÓN, F., Conservar el patrimonio natural (Madrid 2019) 175 y ss.

${ }^{19}$ Sobre ello, v. AMENÓS ÁLAMO, J.: "La compensación a los titulares de terrenos incluidos en espacios naturales protegidos. Jurisprudencia reciente”, en GARCÍA DE ENTERRÍA, E. y ALONSO GARCÍA, R., Administración y Justicia. Un análisis jurisprudencial. Volumen I. España, Liber amicorum Tomás-Ramón Fernández (Madrid 2012) 513-536.
} 
El presupuesto de este artículo es la aparición de una demanda renovada por residir en ámbitos con mayor presencia vegetal (y, en su caso, faunística). Esta preferencia ha renacido especialmente a raíz de algunas medidas adoptadas para combatir la pandemia de Covid-19. En concreto, el confinamiento y las distancias sanitarias.

El indicado rechazo de la aglomeración implicará una mayor querencia, en suelo urbano, por una urbanización dispersa o por el incremento de espacios verdes en los ámbitos de edificación maciza. Ahora bien, la principal presión podría concentrarse en los supuesto ${ }^{20}$ constructivos que se admiten en suelo no urbanizable. En concreto, la residencia vinculada al uso agrícola, la instalación turística y el excepcional alojamiento aislado. Si, además, se trata de suelo rústico sometido a una especial protección (por ejemplo, un parque natural legalmente declarado), el atractivo es máximo (especialmente, dadas las posibilidades de teletrabajo). El futuro dirá si la nueva mentalidad genera cambios en la regulación de los conceptos enumerados.

\section{Bibliografía}

- ALLÍ TURRILLAS, J.C., La protección de la biodiversidad. Estudio jurídico de los sistemas para la salvaguarda de las especies naturales y sus ecosistemas (Madrid 2016)

- AMENÓS ÁlAMO, J., El mito legal de la ciudad compacta (Barcelona 2015)

- AMENÓS ÁLAMO, J., La compensación a los titulares de terrenos incluidos en espacios naturales protegidos. Jurisprudencia reciente, en GARCÍA DE ENTERRÍA, E. y ALONSO GARCÍA, R., Administración y Justicia. Un análisis jurisprudencial. Volumen I. España, Liber amicorum TomásRamón Fernández (Madrid 2012) 513-536

- BAÑO LEÓN, J.M., Derecho urbanístico común (Madrid 2009)

- BRUEGMANN, R., Sprawl. A compact history (The University of Chicago 2005).

- HARPER, K., The Fate of Rome: Climate, Disease, and the End of an Empire (Princeton 2017)

- LE CORBUSIER, Principios de urbanismo (La Carta de Atenas), trad. castellana de Juan-Ramón CAPELLA (Barcelona 1981)

- LÓPEZ-RAMÓN, F., Conservar el patrimonio natural (Madrid 2019)

- MASOLIVER, J.R., "De quan Montcada fou peonera", en Perfil de sombras (Barcelona 1994) 4751

- MEGAHED, N.A. y GHONEIM, E.M., Antivirus-built environment: lessons learned from Covid19 pandemic, Elsevier public Health emergency Collection (2020) disponible en https://www.ncbi.nlm.nih.gov/pmc/articles/PMC7313520/.

- OECD: Housing amid Covid-19: policy responses and challenges, 2020 (22 de Julio), disponible en https://read.oecd-ilibrary.org/view/?ref=135_135322-lju8yj5sib\&title=Housing-Amid-Covid-19Policy-Responses-and-Challenges.

- PARADA, R. y LORA-TAMAYO, M., Derecho Administrativo III. Bienes públicos. Derecho urbanístico (Madrid 2019)

- PAREJA I LOZANO, C., Régimen del suelo no urbanizable (Madrid 1990)

- SITIAN LY y YITCHEN SU, The impact of the Covid-19 pandemic on the demand for density: evidence from the U.S. housing market, Federal Reserv. Bank of Dallas (July 27, 2020) Disponible en internet: https://www.dallasfed.org/-/media/documents/research/papers/2020/wp2024.pdf

- ZOIDO,F., DE LA VEGA, S., PIÑEIRO, A., MORALES, G., MAS, R., LOIS, R.C. y GONZÁLEZ, J.M., Diccionario de urbanismo. Geografía urbana y ordenación del territorio (Madrid 2013) 